Nordic Journal of Religion and Society (2012), 25 (2): 131-150

Ingrid Storm and David Voas

\title{
THE INTERGENERATIONAL TRANSMISSION OF RELIGIOUS SERVICE ATTENDANCE
}

\begin{abstract}
Religious change is often described with aggregate figures on affiliation, practice and belief. Such studies tell us that secularisation happens because each cohort is less religious than the one before, and that socialisation in childhood and habits formed in young adulthood are overwhelmingly responsible for religious decline. In this article we use data from the International Social Survey Programme to consider the extent and magnitude of religious decline at the level of families, whether parental influence is greater in more religious countries, and which individual variables influence the intergenerational transmission of religious practice and whether these vary between different countries. We find that secularisation happens largely because many people are a little less religious than their parents, and relatively few are more religious. We also find that the patterns of transmission are remarkably stable: parents are no more influential in religious countries than in nonreligious countries, and there is no indication that they have lost influence over time.
\end{abstract}

Keywords: religion, socialisation, intergenerational transmission, secularisation, surveys

\section{Introduction}

Across most of the Western world, each generation reaching adulthood is less religious than the one before. We also know that parents and families are crucial in the process of religious socialisation: the best predictor of anyone's religious involvement is how they were raised (Voas and Crockett 2005). It is easy to assume that religious socialisation in families is less effective now than it was in the past, and less effective in secular countries than in religious ones. The scope and intensity of exposure to popular culture, transmitted in ways undreamt of a few decades ago, makes it natural to suppose that young people are less influenced by their parents than before. Surprisingly, though, this common hypothesis is not supported by the evidence we will consider.

We are accustomed to seeing religious change described with aggregate figures on affiliation, practice and belief, but it is interesting to consider how those attributes are generated from the ground up. We will be focusing on three research questions. The first relates to secularization at the level of families: does religious decline happen 
because a few people become much less religious than their parents, or because many people are a little less religious?

The second question concerns the effect of parental religiosity relative to other determinants of religious involvement. In particular, are parents more influential in religious countries and less so in secular ones? If the answer is 'yes', then secularisation can be explained at least in part by an erosion of primary socialisation as a stimulus to religious commitment. If the answer is 'no', then the proximal causes of secularisation must be sought elsewhere. Perhaps it is the general culture that matters, and the effect of upbringing is merely a given, something that explains a similar amount of variance in all developed societies.

To test the answer to this question while controlling for other factors, we will consider additional attributes of individuals, their parents and the environment. Our third research question concerns which characteristics promote or impede intergenerational religious transmission, and whether these effects vary between a relatively secular country (e.g. Great Britain) and a relatively religious one (e.g. the United States).

Previous studies show interesting cross-national trends of religious stability and decline, but the aggregate rates tell us little about the role of religious socialisation in determining the pace and pattern of religious decline, nor do they tell us whether there are national differences in how religious change takes place at the level of families and individuals. Since religious decline has been shown to be mainly the result of cohort differences, we may need to look at how effective parents are at transmitting their religious behaviours to their children in order to understand the differences between developed countries.

Research on the intergenerational transmission of religiosity could offer important insights into past and future trends in religious behaviour as well as national differences in patterns of secularisation. The first part of the paper discusses ways of studying religious socialisation, the second part summarises respondent and parental attendance from an international dataset of 40 countries, the third part concentrates on the transmission of self-reported religiosity in four European countries with different religious profiles (Great Britain, Denmark, the Netherlands and Ireland), and finally we explore individual characteristics associated with church attendance in Great Britain and the United States.

\section{Studying religious socialisation using survey data}

Socialisation in childhood and adolescence, including observation, participation and education, is the most important process by which religious beliefs and behaviours are transmitted from one generation to the next. According to social learning theory, the strength and consistency of the parents' behaviour determines the extent to which religious and political values are transmitted to the next generation (Jennings et al. 2009: 783). Nonetheless, one should take care not to ignore the importance of peer groups, siblings and social context as children grow older and become more independent. The direct influence of parents' behaviour on children's values and behaviour in adult life 
is a contested topic, and a number of twin and adoption studies in behavioural genetics finds that a substantial portion of variation in complex behavioural traits is not accounted for by the effects of either genes or family environment (Turkheimer 2000: 160). However, the influence of parents is also indirect (Jennings et al. 2009: 795) and affects which other adults and children they encounter, which schools they attend, what media they consume and in short how likely they are to have religious influences outside the family. While we can measure parental religiosity, it is very difficult to measure local or peer group effects using survey data, and many individual characteristics will be unobserved.

A noteworthy feature of religious socialisation is that it is aimed at reproduction rather than increase. Unlike health, education and social status, where parents tend to hope for inter-generational improvement, parents are generally most content when their children are religiously similar to themselves. The term 'transmission' is therefore appropriate. Like partisanship and racial identity, religion has high rates of intergenerational reproduction compared to less affect-laden values and behaviours such as opinions on particular topical issues, which are more affected by changing political contexts (Jennings et al. 2009: 785).

Religious service attendance is considered a good measure of religious commitment because it takes time and effort, in contrast to claiming a religious identity or professing beliefs. As a collective activity it also signals belonging to a greater extent than private activities such as prayer. However, measuring churchgoing or other religious service attendance is not without problems. It is notorious that survey respondents over-report their own attendance. Chaves suggests that when asked directly how often they go to services, many people exaggerate their attendance in an attempt to communicate that they «think of themselves as church people» (Chaves 2011: 44). Social desirability bias on this matter may of course be stronger in the US than in most of Europe, since more people in the US are religious. However, as our interest lies not in the absolute levels of attendance, but in comparing parents and their children, this issue should not interfere with the analysis. Since the parents' and the respondent's attendance are based on responses from the same person, we expect the same response bias to affect both equally.

One might argue that deriving parental attendance from retrospective questions is fraught with problems such as recall bias. Ideally we would have long-running household panel studies to study the relationship between parents and their adult children. Unfortunately, such surveys are very rare and many have high attrition rates, which could make them biased. In their absence, retrospective questions such as «when you were a child, how often did your mother attend religious services?» can serve as a proxy for longitudinal data collection. Iannaccone (2003) convincingly argues that the quality of the data is higher than it might seem, and shows with a variety of different tests that «when the primary goal is to generate a profile of aggregate trends and turning points ... retrospective methods will often yield extremely robust results» (Iannaccone 2003: 13). Unlike other childhood events, repeated occurrences such as the religious service attendance of one's parents are not likely to be forgotten, even if they date back 50 or more years. In any event, in the absence of cross-national household 
panel data on church attendance, these retrospective proxy reports are the best indicators of micro-level religious transmission available.

\section{Data and methods}

The International Social Survey Programme (ISSP) is a continuing, annual programme of cross-national collaboration in surveys carried out by research organisations in the participating countries, often as part of high quality national surveys such as the General Social Survey in the US and the British Social Attitudes survey in Britain. A module on religion was included in 1991, 1998 and 2008. The newest dataset from 2008 includes nearly 60000 respondents from 40 countries. In each of the countries a representative sample of around 2000 respondents was surveyed about their religious faith, practices, beliefs, affiliations and traditions in addition to standard sociodemographic variables. For most of the analyses we use the dataset from 2008. In the multivariate analysis, we use data pooled from all three years and control for survey year.

The ISSP is the only multi-national survey to include questions about the religiosity of the respondent's parents (Iannaccone 2003). The question is «How often do you attend religious services?» with nine response categories ranging from «Never» to «Several times a week» ${ }^{1}$. In addition, the respondents were asked about each of their parents: "When you were a child, how often did your mother/father attend religious services?», with the same nine response categories. The average attendance of both parents is used for most of the analyses ${ }^{2}$.

We also have data on the religiosity of parents and respondents from four countries in the sample. In 2008, an extention of 24 questions funded by NORFACE (New Opportunities for Research Funding Agency Co-operation in Europe) was added to the ISSP survey in Britain, the Netherlands, Denmark, Ireland and Northern Ireland. Two of these questions ask about the religiosity of each of the respondent's parents: «When you were a child, how religious was your mother / father?» with six response categories ranging from «Extremely religious» to «Extremely non-religious». The questions correspond to a question put to the respondents themselves in the main questionnaire: "Would you describe yourself as ...», with the same six response categories. As with the religious attendance variable, the average religiosity of the parents is calculated for comparison with the respondent's own religiosity.

\section{Respondent and parental attendance from the ISSP 2008}

Frequency of attendance at religious services is a commonly used measure of religious involvement and one of the most straightforward yardsticks for comparing parents' and children's religiosity. In the whole international sample, the mean attendance is 3.66 $(\mathrm{sd}=3.02)$, which corresponds to a few times a year. Parental attendance ${ }^{3}$ is generally higher than that of respondents, with a mean of $4.56(\mathrm{sd}=2.91)$, which equals a little less often than monthly. There are of course large individual differences in transmis- 
sion rate, but overall there are many respondents $(46.5 \%)$ who attend less than their parents did and relatively few who attend more $(21.9 \%)$.

Figure 1 shows the mean attendance of respondents by each level of parental attendance. The graph shows the religiosity of parents on the horizontal axis and the religiosity of children on the vertical axis, and the lines that slopes upward represent the relationship between the two for men and women respectively. The size of the circles represents the number of respondents who fall into each category of parental attendance. Not surprisingly, the more the parents attend religious services, the more their children attend too, on average. The association is very strong, although behind these averages there is a good deal of variation.

Respondents are pushed in two directions: by their parents, represented by the dotted diagonal line of perfect transmission, and by the religious environment, represented here by the horizontal line. The more there is regression to the national mean, the flatter the line; the more important the parental influence, the steeper the slope. ISSP respondents as a whole seem to be right in between, suggesting that parents and national culture are almost equally important influences. The association is strikingly linear and there is no indication that parents have more influence in homes where religion is a more salient issue, as one would expect from social learning theory (Jennings et al. 2009).

The gap between the lines for men and women shows that gender is an important variable. In itself this is no surprise, as several studies have shown that with the exception of Jews and Muslims, women are generally more religiously active than men (Walter and Davie 1998; Sullins 2006). What is interesting is that the lines are so parallel, showing that there is no interaction effect between parental attendance and gender. Rather, women have a slightly higher religious practice whatever the level of parental attendance.

There is a slight generational difference as well, with older people being more likely to attend than younger people. However, this too affects only the intercept and not the slope. If one compares the youngest cohort (18-29) and the oldest (60+), the two parallel lines look very similar to the ones for men and women in Figure 1. This generational comparison suggests that parents have not declined in importance relative to other factors. Average attendance has dropped for people of all levels of parental religiosity, but the degree of parental influence (as represented by the slope of the graph) is unchanged. 


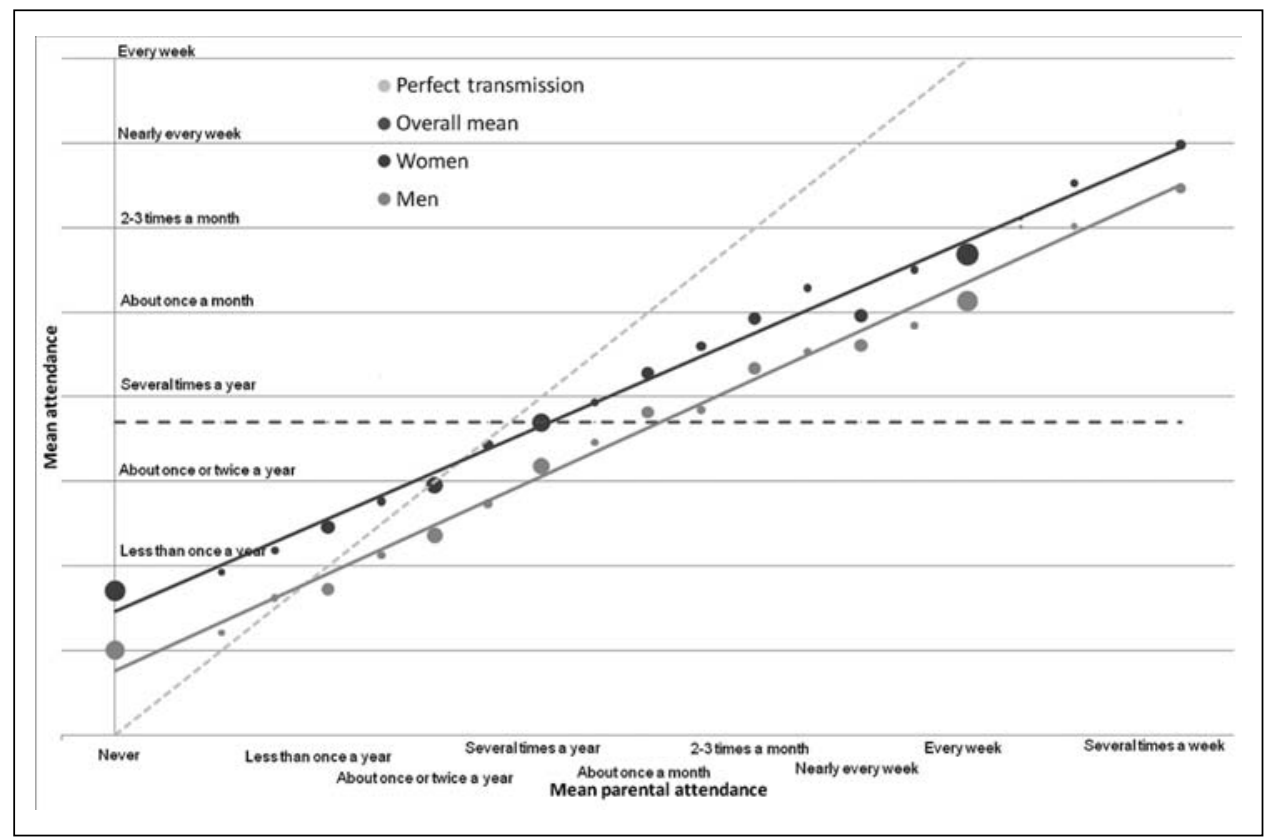

Figure 1. Average attendance by parental attendance ISSP 2008

While a majority of people in the whole ISSP sample have parents who attend as often as or more often than themselves, it is reasonable to suppose that there may be significant cross-national variation. One useful measure is the difference between the percentage in each country who attend less than their parents and the percentage who attend more. This is shown in the first column in Table 1. In most Western countries the net gap is between 25 and 50 percentage points. (Belgium (Flanders) and Ukraine are outliers on either side.) This gap is substantial, but the overall attendance difference between respondents and their parents is only one to one and a half points on the $0-10$ scale (shown in the second column). As the categories are fairly close, this means that the generational decline is fairly slow. There are a few (mainly less developed or non-Western) countries with a slight increase, but nowhere in the sample does attendance increase across the generations by more than half a point on the scale. The answer to the first question posed at the outset is simple: religious decline is the result of many people being, on average, a little less religious than their parents. Table 1 also shows, in addition to the national mean attendance, the bivariate correlations between parents' and respondent's attendance. In answer to the second question, there is no clear association between the values in these two columns, and we have no indication that parents are less influential in secular countries. 
Ingrid Storm and David Voas: The intergenerational transmission

Table 1. Difference in attendance between parents and respondents by country

\begin{tabular}{|c|c|c|c|c|c|}
\hline Country & $\begin{array}{l}\% \text { R< par- } \\
\% \text { R>par }\end{array}$ & $\begin{array}{c}\text { Mean gap } \\
\text { R-par }\end{array}$ & $\begin{array}{l}\text { Correlation } \\
\mathrm{R} \text { and par }\end{array}$ & $\begin{array}{c}\text { Mean } \\
\text { attendance }\end{array}$ & $\mathbf{N}$ \\
\hline Belgium/ Flanders & 71.15 & -3.07 & 0.447 & 1.965 & 1175 \\
\hline France & 50.18 & -1.65 & 0.511 & 1.669 & 2258 \\
\hline W-Germany-West & 46.20 & -1.72 & 0.410 & 3.013 & 1065 \\
\hline Ireland & 45.90 & -1.90 & 0.364 & 5.418 & 1989 \\
\hline Portugal & 44.81 & -1.60 & 0.411 & 3.985 & 953 \\
\hline Hungary & 42.93 & -1.42 & 0.528 & 2.204 & 962 \\
\hline Great Britain & 41.77 & -1.61 & 0.359 & 2.027 & 1573 \\
\hline Austria & 41.58 & -1.34 & 0.586 & 3.475 & 914 \\
\hline Switzerland & 41.39 & -1.50 & 0.374 & 3.570 & 877 \\
\hline Norway & 39.86 & -1.04 & 0.537 & 1.844 & 981 \\
\hline Spain & 38.95 & -1.64 & 0.343 & 3.784 & 1714 \\
\hline Poland & 38.29 & -1.31 & 0.389 & 5.624 & 1197 \\
\hline Netherlands & 38.20 & -1.67 & 0.467 & 3.041 & 1774 \\
\hline Australia & 37.56 & -1.37 & 0.441 & 2.187 & 1530 \\
\hline Italy & 32.03 & -1.18 & 0.536 & 4.312 & 1000 \\
\hline Slovenia & 31.48 & -1.17 & 0.536 & 3.653 & 1007 \\
\hline Czech Republic & 31.35 & -0.98 & 0.684 & 1.591 & 1327 \\
\hline Germany-East & 29.33 & -1.05 & 0.414 & 1.298 & 433 \\
\hline South Africa & 29.03 & -1.16 & 0.186 & 5.065 & 2463 \\
\hline Cyprus & 28.56 & -0.72 & 0.498 & 4.601 & 935 \\
\hline Sweden & 27.36 & -0.73 & 0.530 & 2.043 & 1100 \\
\hline New Zealand & 27.32 & -1.04 & 0.386 & 2.706 & 937 \\
\hline Israel, Jews & 26.73 & -1.07 & 0.521 & 3.383 & 969 \\
\hline Slovak Republic & 26.41 & -1.00 & 0.600 & 4.186 & 1084 \\
\hline Northern Ireland & 26.37 & -1.01 & 0.374 & 5.211 & 909 \\
\hline Uruguay & 26.35 & -0.80 & 0.301 & 1.975 & 978 \\
\hline United States & 25.21 & -1.01 & 0.333 & 4.388 & 1313 \\
\hline Chile & 25.21 & -1.12 & 0.160 & 3.962 & 1334 \\
\hline Mexico & 15.46 & -0.53 & 0.406 & 5.375 & 1306 \\
\hline Denmark & 14.06 & -0.47 & 0.435 & 2.493 & 1871 \\
\hline Finland & 13.26 & -0.19 & 0.456 & 2.700 & 1018 \\
\hline Croatia & 12.16 & -0.34 & 0.522 & 4.516 & 1127 \\
\hline Latvia & 2.93 & -0.09 & 0.463 & 2.543 & 888 \\
\hline South Korea & 2.55 & 0.32 & 0.239 & 3.505 & 1453 \\
\hline Turkey & 0.98 & -0.20 & 0.353 & 6.632 & 1333 \\
\hline Israel, Arabs & 0.82 & -0.50 & 0.321 & 5.756 & 122 \\
\hline Russia & -2.67 & 0.17 & 0.396 & 1.926 & 713 \\
\hline Taiwan & -7.03 & 0.28 & 0.218 & 4.434 & 1749 \\
\hline Dominican Republic & -8.92 & 0.12 & 0.475 & 5.786 & 2052 \\
\hline Philippines & -9.22 & 0.28 & 0.231 & 6.788 & 1117 \\
\hline Japan & -12.73 & 0.23 & 0.432 & 2.965 & 982 \\
\hline Ukraine & -15.81 & 0.59 & 0.416 & 3.420 & 1670 \\
\hline
\end{tabular}

Source: ISSP 2008

Notes: $\mathrm{R}=$ respondent's attendance, par $=$ parental attendance 


\section{Respondent and parental religiosity in four European countries}

Because religious service attendance only measures one aspect of the multifaceted concept of religion, a further test of the effect of parental religiosity relative to other influences uses a different measure of religious commitment. In the countries where the extended NORFACE questionnaire was used, we can also measure the relationship between self-reported religiosity and the religiosity of parents. Great Britain, the Netherlands, Denmark and Ireland have very different religious profiles, as can be seen in the mean national attendance figures in Table 1 . The percentage distributions of parents' and respondents' religiosity also differ. In Ireland a clear majority of both generations is at least somewhat religious. The Dutch sample is also fairly religious, at least in the parental generation, whereas in Denmark and Britain the larger number of nonreligious people makes the distribution more symmetrically bell-shaped.

Do these differences in national religious culture affect the transmission of religion and religious practice from parents to children? In Figure 3 the mean levels of respondent religiosity are plotted against the religiosity of their parents for these four countries. Two hypotheses come to mind. First, the intercept on the graph just described should be higher in more religious countries: for any given level of parental religiosity, children will be more religious in the more religious country. Secondly, the slope might be steeper: a religious culture will reinforce domestic religious socialisation, and the combination of parental and cultural influences might mean that religious parents are especially successful at reproducing their faith in nations like Ireland. ${ }^{4}$

The lines in Figure 2 are remarkably similar, implying that national differences matter very little to the pattern of religious transmission. Respondents who describe their parents on average as neither religious nor nonreligious say on average the same about themselves, whereas those whose parents are both extremely religious are on average «very religious» themselves regardless of which of the four countries they live in. 


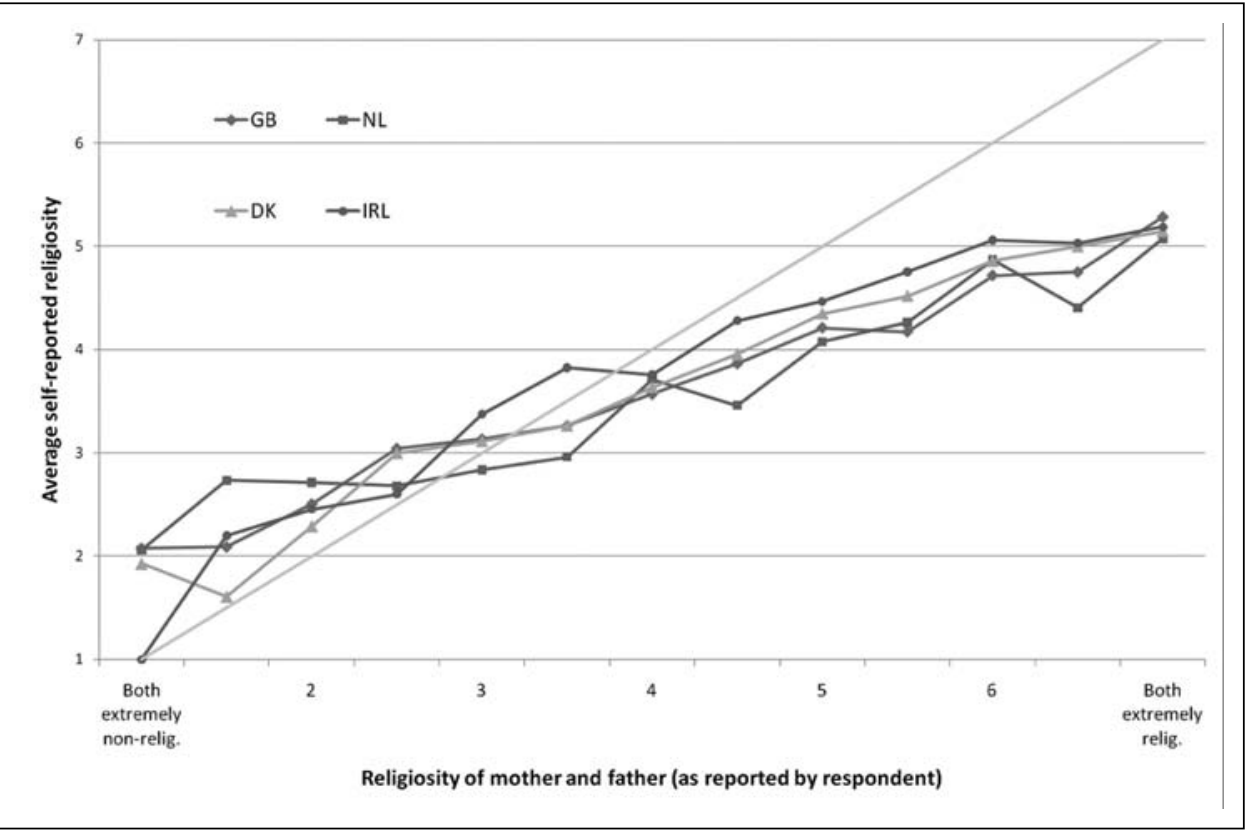

Figure 2. Self-reported religiosity by average parental religiosity ISSP 2008 (GB: N=1796; NL: N=1719; DK: N=1762; IRL: N=1939)

The similarities between these countries raises the question of whether the rate of transmission has been constant or has changed over time. If secular environments are less conducive to religious socialisation than religious ones we should expect that it becomes increasingly difficult (or perhaps less desirable) for parents to pass on their religious beliefs and behaviours to their offspring. On the other hand, the potential for decline is greater the more religious the average parent.

Figure 3 shows the net loss in religiosity between parents (average of mother and father) and respondents in the four countries by the respondent's birth year. Values represent the difference between the percentage of respondents whose parents are more religious than they are and the percentage whose parents are less religious. As the graph shows, the generation gap in religiosity is apparent in all four countries even for people born early in the $20^{\text {th }}$ century, but its exact pattern varies. Religious attendance appears to have been declining at a faster rate in Ireland and the Netherlands than in Britain and Denmark, possibly because the starting point was higher. As more of the population were religious attenders to begin with, there was less opportunity for increase, and greater potential for loss. The rate of change has been relatively constant in some countries, like Britain, but less so in the Netherlands, where the decline peaked for respondents born in the 1950s. This expansion of the Dutch welfare state in the 1960s was associated with a simultaneous decline in the importance of religious institutions, and the Netherlands went from being one of the most religious countries in Europe to one of the most secular in just one generation (Van Rooden 2003: 125). These results indicate that declining parental influence, while being a potential contrib- 
uting factor in some countries, does not represent a general cause of secularisation. It is thus necessary to look for other causes of religious decline.

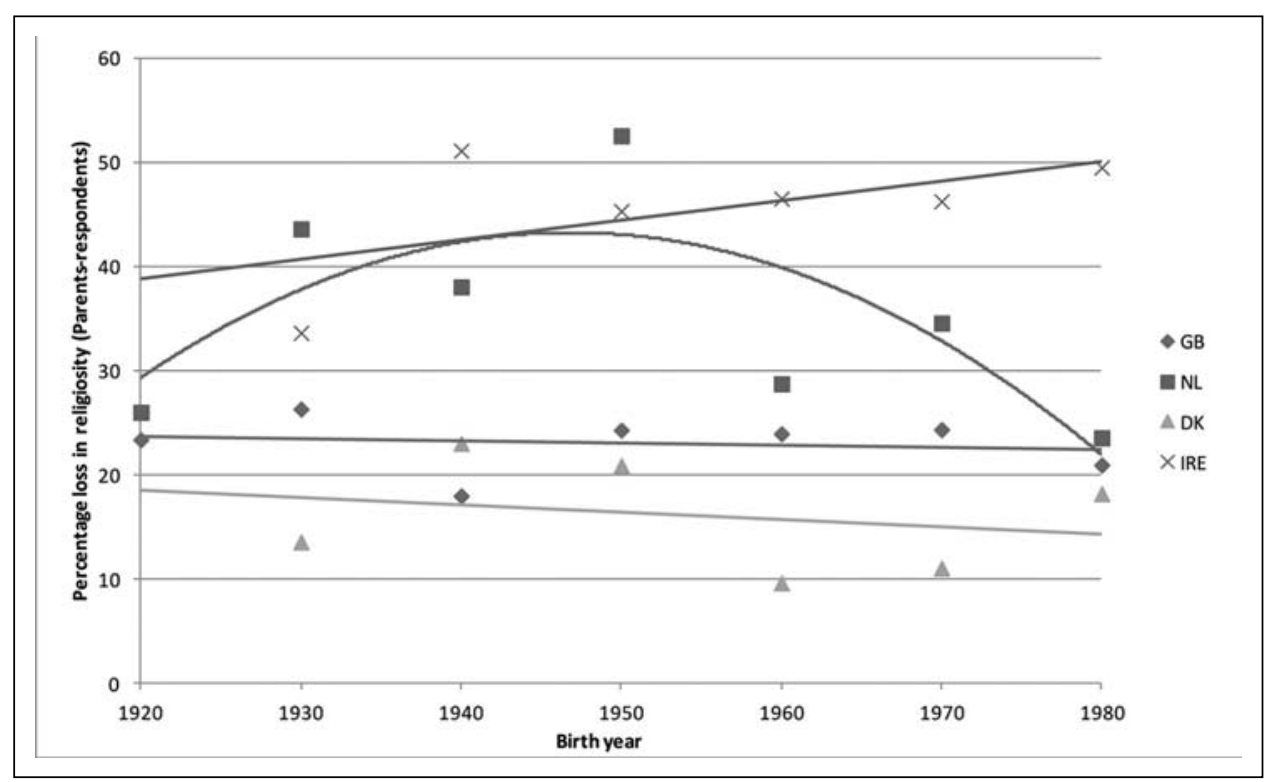

Figure 3. Net loss in religiosity (\% less religious - \% more religious than parents) by birth year

ISSP 2008 (GB: N=1796; NL: N=1719; DK: N=1762; IRL: N=1939)

\section{Multivariate analysis of religious attendance in US and Great Britain}

There is general agreement that cultural context influences the successful transmission of church attendance to some extent. However, the patterns of transmission in the European countries that we have examined so far are strikingly similar. An interesting question is what happens when we look at the the US, which is known to have an exceptionally stable level of religiosity compared to Europe (Putnam and Campbell 2010:75). More than a quarter of Americans from all three ISSP religion surveys report attending religious services every week or more, whereas the comparable figure for Britain is 11 per cent. In the following section, a detailed comparison is made between religious attendance in the US and Great Britain using multivariate models that include parental influence, denominational affiliation and sociodemographic variables.

In Figure 4 the respondents' mean church attendance is plotted against the average church attendance of their parents. As in Figure 1, if parents have more influence, we would expect the plotted line to be steeper and closer to the diagonal, whereas if influences outside the family are more important, the line should be flatter and closer to the national mean. 
In both Britain and the US the lines representing the church attendance of respondents relative to their parents have strong positive slopes, but with a marked regression towards the mean. In general the lines are very similar and consistent with the other findings from the whole ISSP sample. People are more likely to attend in the US than in Great Britain, but the difference in attendance is almost exactly the same between the two countries whether the parents attend never (1.64) or weekly (1.62).

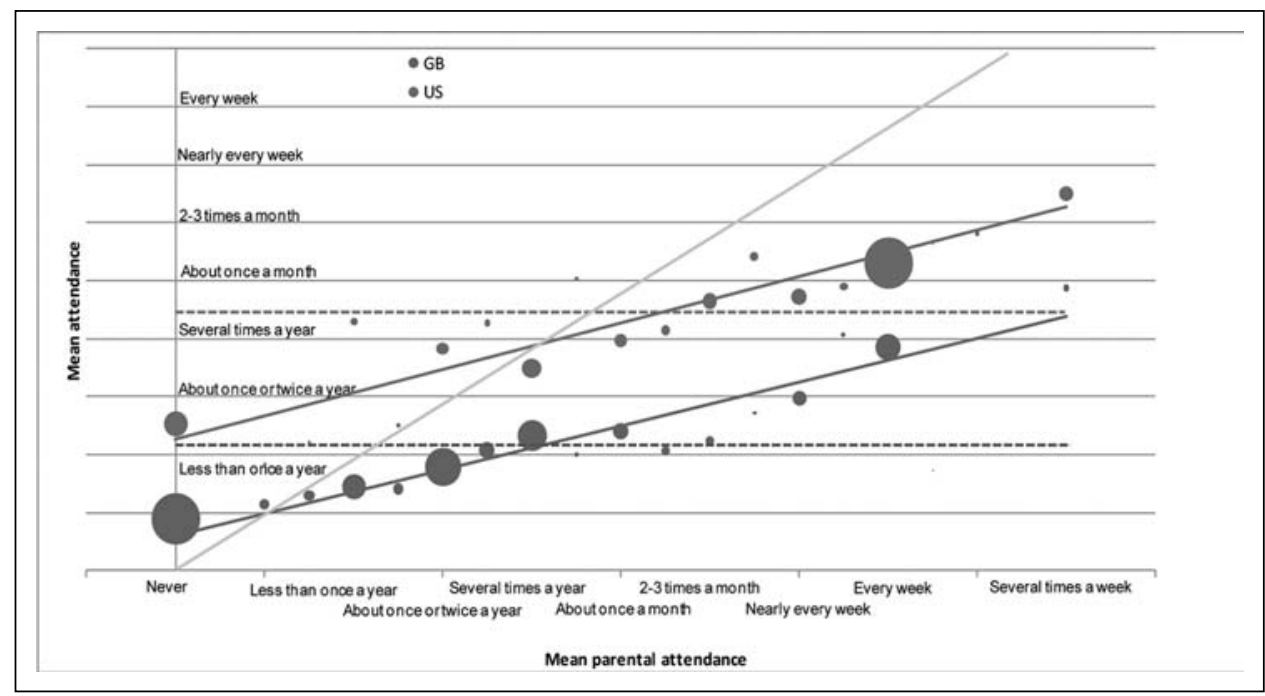

Figure 4. Average attendance by parental attendance in Britain and the US ISSP 2008 (US: N=1313, GB: N=1573)

Aside from being brought up in a religious home and being affiliated with a religion, there are other sociodemographic factors that influence a person's religious attendance habits in adult life. In examining the relative influence of parents, we must consider the different factors that contribute to the religious behaviours of individuals in a multivariate analysis.

Firstly, a consistent finding across the Western world is that women are generally more religious than men on a wide range of measures (Walter and Davie 1998; Sullins 2006). Moreover, there may be a difference in the way mothers and fathers transmit religiosity to their offspring. In an American panel study Willits and Crider (1989: 74) found that mother's attendance was a better predictor of church attendance in young adulthood than father's attendance. Francis and Brown (1991: 115) found the same result in a study of adolescents in England.

Structural location should also be taken into account, however. DeVaus and McAllister (1987) found that lower female workforce participation is an important explanatory factor for the gender gap. Education is an even more consistent predictor, and is associated with religious service attendance in both the US and the UK (Sacerdote and Glaeser 2001). People are also more likely to attend if they are married or have children (Chaves 2011: 52). 
Several studies show that two parents attending religious services are more likely to have churchgoing children than if only one parent attends (Francis and Brown 1991; Voas and Crockett 2005; Voas and Storm 2012). Moreover, agreement between the parents (Hoge et al. 1982; Myers 1996), and consistency of beliefs and behaviours (Bader and Desmond 2006) are important predictors of successful transmission of religious involvement. Children whose parents have the same religious affiliation are more likely than children of «mixed marriages» to continue attending religious services as adults (Putnam and Campbell 2010: 142).

According to Willits and Crider (1989: 79), the influence of parents in childhood is not as important as the church attendance of one's spouse. Even if the causal direction is almost impossible to disentangle without detailed panel data, it is an interesting measure of the respondent's current social influences and habits.

Another important feature of the current social environment is the church itself. Hoge et al. (1982) point out that religious socialisation takes place within denominational subgroups, and these should be expected to have different rates of intergenerational transmission. For example, conservative evangelical Protestant denominations in America have been more successful than mainline denominations in retaining young people in the church (Chaves 2011: 10).

The question about denominational affiliation was worded differently in the two countries. In Britain the respondents were asked «Do you regard yourself as belonging to any particular religion? [if 'yes':] Which?», whereas in the US they were asked what their religious preference was. In the US model the Protestant denominations have been divided into Mainline, Evangelical and Black Protestants. In Britain the Protestant category includes Church of England, Baptists, Methodists and Presbyterians. All other non-Catholic denominations are in the «Other Christian» category. The distribution of religious affiliation is considerably different in Britain and the United States. In the British ISSP data pooled from 1991, 1998 and 2008, 39 per cent stated that they do not regard themselves as belonging to a religion. By contrast only 11 per cent of the American sample has no religion.

Nonetheless, denominational categories often include people who are not very committed to or interested in the religion, and thus do not necessarily reflect the meaning of the religion for the individual adherent (Ploch and Hastings 1998: 309310). For religion to have personal salience and motivational power beyond social conventions, religious beliefs must also be present, and thus we include the respondent's belief in God.

All the variables mentioned above were included in a linear regression model with the 9-point scale of respondent's religious service attendance as the dependent variable. The independent variables were introduced in three steps. The first model only controls for sociodemographic variables, the second introduces the main variables of interest, namely the attendance and religiosity of parents and spouses, and finally the third model tests how these associations hold up when belief in God and denomination are introduced. The results for Britain are shown in Table 2 and for the US in Table 3.

Most of the categorical variables are dummy variables. However, Belief in God is coded on a scale from 1) «I don't believe in God» to 5)《I know God exists and have 
no doubts about it» ${ }^{5}$. Education is also treated as a continuous variable with categories ranging from 0) «No qualification» to 5) «Degree» in Britain and from 0) «Less than high school» to 4) «Graduate degree» in the $\mathrm{US}^{6}$. There are some other minor differences in the variables between the two countries. In Britain the respondents were asked about the religion of their partners regardless of their marital status, whereas in the US they were only asked about their spouse. The variable labelled «Children in household» was recoded from different variables. In Britain it measures whether any other people in the household are sons or daughters of the respondents, whereas in the US it measures whether any household members are under 18 years old. The «Parents same religion» variable is coded «1» when the parents had the same religion (not including 'none') as each other when the respondent was a child. «Parents different religion» applies when one parent had no religion or a different religion from the other. The reference category is that neither parent had a religious affiliation. Collinearity should not be a problem in these models, as the only Pearson's correlations above 0.6 are the correlations between father's attendance and mother's attendance (GB: 0.706, US: 0.633).

The results are very similar in Britain and the US. In particular the influence of parents seems almost identical. Attendance was somewhat higher in 1991, but this effect is wholly mediated by affiliation and so is not significant in either country in the third model. In both countries, people born before 1940 are more likely to attend church than those born later, even controlling for parental religious activity. While an age effect might be responsible, previous studies indicate that it is primarily a cohort effect (King-Hele 2011). The magnitude of these effects seems similar in the two countries, despite the greater secularisation in Britain. A possible explanation is that because churchgoing in Britain is already low even among older respondents, the potential for decline is likewise reduced.

Women are more likely than men to attend in both countries, if slightly more so in Britain, but the effectiveness of intergenerational transmission does not appear influenced by the gender of the parent. Married people are also more likely to attend, especially if their spouse or partner share their religious affiliation. Education and nonwhite ethnicity also significant increases attendance in both countries, as does employment, if less so when controlling for religiosity. As one would expect, belief in God has a positive association with church attendance in both countries, and all the religious affiliations are highly positively associated. There are some differences between the denominations and the highest coefficient in the US is for Evangelical Protestants, who are well known to be more active church attenders than Mainline Protestants and Catholics (Greeley and Hout 2006). In general, however, the models appear very similar despite the differences between the religious landscape in these two countries.

The final model for Britain is slightly more powerful, accounting for 41 per cent of the variance in church attendance, compared to the US model's 35 per cent. These are high values for social science, though of course they are achieved by explaining one form of religious involvement (attendance) with the help of others (belief and affiliation). Nevertheless, more than half of the variance in church attendance remains unexplained. What the remaining factors are is difficult to say, but geographical differences, 
schooling, friendships and other social networks seem likely candidates (Kelley and de Graaf 1997).

The hypothesis that parents in the US are more successful in transmitting their churchgoing than they are in Britain is supported in one sense but not another. It is true that American children are more similar to their parents in terms of religious practice than their British counterparts. That said, there does not appear to be anything exceptional about the intergenerational transmission of churchgoing in the US. The influence of parents is similar in the two countries. Any differences in retention rates must thus be due to aspects of the cultural environment not controlled for in this model. 
Ingrid Storm and David Voas: The intergenerational transmission

Table 2. Regression: Religious service attendance in Britain

\begin{tabular}{|c|c|c|c|c|c|c|c|c|c|}
\hline \multirow[t]{2}{*}{ DV: R's church attendance } & \multicolumn{3}{|l|}{1} & \multicolumn{3}{|l|}{2} & \multicolumn{3}{|l|}{3} \\
\hline & B & Std. Error & Beta & B & Std. Error & Beta & B & Std. Error & Beta \\
\hline (Constant) & $3.798^{* *}$ & 0.388 & & $1.623^{* *}$ & 0.395 & & -0.504 & 0.371 & \\
\hline \multicolumn{10}{|l|}{ Year (Ref: 2008) } \\
\hline y1991 & $0.395^{* *}$ & 0.117 & 0.071 & 0.116 & 0.117 & 0.021 & 0.124 & 0.105 & 0.022 \\
\hline y1998 & 0.216 & 0.120 & 0.034 & 0.196 & 0.110 & 0.031 & $0.197^{*}$ & 0.099 & 0.031 \\
\hline \multicolumn{10}{|l|}{ Cohort (Ref: 1900-19) } \\
\hline Born 1920-39 & $-0.539^{*}$ & 0.239 & -0.082 & -0.172 & 0.219 & -0.026 & -0.070 & 0.195 & -0.011 \\
\hline Born 1940-59 & $-1.214^{* *}$ & 0.263 & -0.222 & $-0.605^{*}$ & 0.242 & -0.111 & $-0.443^{*}$ & 0.215 & -0.081 \\
\hline Born 1960-79 & $-1.641^{* *}$ & 0.282 & -0.305 & $-0.814^{* *}$ & 0.261 & -0.151 & $-0.624 * *$ & 0.232 & -0.116 \\
\hline Born 1980-99 & $-1.323^{* *}$ & 0.346 & -0.137 & -0.215 & 0.321 & -0.022 & -0.204 & 0.286 & -0.021 \\
\hline Gender: Female & $0.525^{* *}$ & 0.094 & 0.101 & $0.504^{* *}$ & 0.086 & 0.097 & 0.113 & 0.078 & 0.022 \\
\hline Education qualification & $0.242^{* *}$ & 0.027 & 0.168 & $0.181^{* *}$ & 0.025 & 0.126 & $0.202^{* *}$ & 0.022 & 0.140 \\
\hline \multicolumn{10}{|c|}{ Marital status (Ref: Not married) } \\
\hline Married & $0.479 * *$ & 0.127 & 0.092 & -0.042 & 0.134 & -0.008 & $0.278^{*}$ & 0.120 & 0.053 \\
\hline Divorced or widowed & 0.174 & 0.168 & 0.024 & 0.267 & 0.156 & 0.037 & -0.017 & 0.140 & -0.002 \\
\hline Children in household & 0.164 & 0.103 & 0.031 & 0.160 & 0.095 & 0.031 & 0.163 & 0.084 & 0.031 \\
\hline Ethnicity: White & $-1.961^{* *}$ & 0.200 & -0.171 & $-1.113^{* *}$ & 0.187 & -0.097 & -0.371 & 0.191 & -0.032 \\
\hline \multicolumn{10}{|l|}{ Employment (Ref: Employed) } \\
\hline Unemployed & -0.041 & 0.208 & -0.003 & 0.035 & 0.190 & 0.003 & -0.007 & 0.169 & 0.000 \\
\hline Homemaker & $0.326^{*}$ & 0.166 & 0.037 & 0.121 & 0.152 & 0.014 & 0.172 & 0.135 & 0.019 \\
\hline Retired & $0.352^{*}$ & 0.162 & 0.054 & 0.244 & 0.148 & 0.038 & 0.179 & 0.132 & 0.028 \\
\hline Student & 0.082 & 0.281 & 0.005 & 0.065 & 0.258 & 0.004 & -0.223 & 0.230 & -0.015 \\
\hline Mother's attendance & & & & $0.199 * *$ & 0.023 & 0.199 & $0.099 * *$ & 0.021 & 0.099 \\
\hline Father's attendance & & & & $0.174^{* *}$ & 0.024 & 0.172 & $0.092^{* *}$ & 0.021 & 0.091 \\
\hline \multicolumn{10}{|c|}{ Parents' religion (Ref: No religion) } \\
\hline Mum and dad same religior & & & & -0.131 & 0.118 & -0.025 & -0.176 & 0.106 & -0.034 \\
\hline Mum and dad different reli & gion & & & 0.072 & 0.132 & 0.011 & 0.002 & 0.118 & 0.000 \\
\hline \multicolumn{10}{|c|}{ Partner's religion (Ref: No partner) } \\
\hline Partner's religion same as $R$ & & & & $0.851^{* *}$ & 0.176 & 0.142 & -0.084 & 0.164 & -0.014 \\
\hline Partner's religion different & & & & -0.034 & 0.168 & -0.006 & $-0.327^{*}$ & 0.150 & -0.059 \\
\hline Partner has no religion & & & & $-0.688 * *$ & 0.155 & -0.124 & -0.198 & 0.139 & -0.035 \\
\hline Belief in God & & & & & & & $0.589 * *$ & 0.035 & 0.300 \\
\hline \multicolumn{10}{|c|}{ Denomination (Ref: No religion) } \\
\hline Protestant & & & & & & & $0.878^{* *}$ & 0.111 & 0.163 \\
\hline Catholic & & & & & & & $1.784^{* *}$ & 0.148 & 0.208 \\
\hline Other Christian & & & & & & & $1.764^{* *}$ & 0.142 & 0.203 \\
\hline Other religion & & & & & & & $1.610^{* *}$ & 0.225 & 0.128 \\
\hline$R$ square & 0.108 & & & 0.257 & & & 0.414 & & \\
\hline N & 3082 & & & 3082 & & & 3082 & & \\
\hline
\end{tabular}


Nordic Journal of Religion and Society 25:2

Table 3. Regression: Religious service attendance in the US

\begin{tabular}{|c|c|c|c|c|c|c|c|c|c|}
\hline \multirow[t]{2}{*}{ DV: R's church attendance } & \multicolumn{3}{|l|}{1} & \multicolumn{3}{|l|}{2} & \multicolumn{3}{|l|}{3} \\
\hline & B & Std. Error & Beta & B & Std. Error & Beta & B & Std. Error & Beta \\
\hline (Constant) & $3.496^{* *}$ & 0.365 & & $1.598^{* *}$ & 0.375 & & $-1.434^{* *}$ & 0.372 & \\
\hline \multicolumn{10}{|l|}{ Year (Ref: 2008) } \\
\hline y1991 & $0.320^{*}$ & 0.126 & 0.055 & 0.146 & 0.117 & 0.025 & -0.011 & 0.107 & -0.002 \\
\hline y1998 & 0.228 & 0.120 & 0.039 & 0.095 & 0.112 & 0.016 & 0.041 & 0.102 & 0.007 \\
\hline \multicolumn{10}{|l|}{ Cohort (Ref: 1900-19) } \\
\hline Born 1920-39 & -0.155 & 0.261 & -0.021 & -0.062 & 0.243 & -0.008 & -0.190 & 0.221 & -0.025 \\
\hline Born 1940-59 & $-0.885^{* *}$ & 0.276 & -0.158 & $-0.702^{* *}$ & 0.257 & -0.125 & $-0.822 * *$ & 0.233 & -0.147 \\
\hline Born 1960-79 & $-1.044^{* *}$ & 0.293 & -0.184 & $-0.768^{* *}$ & 0.273 & -0.135 & $-0.871^{* *}$ & 0.248 & -0.153 \\
\hline Born 1980-99 & $-1.066^{* *}$ & 0.364 & -0.099 & $-0.936^{* *}$ & 0.339 & -0.087 & $-0.843^{* *}$ & 0.307 & -0.078 \\
\hline Gender: Female & $0.345^{* *}$ & 0.099 & 0.063 & $0.345^{* *}$ & 0.092 & 0.063 & -0.019 & 0.085 & -0.004 \\
\hline Education qualification & $0.190^{* *}$ & 0.041 & 0.081 & $0.147^{* *}$ & 0.038 & 0.063 & $0.257^{* *}$ & 0.036 & 0.110 \\
\hline \multicolumn{10}{|c|}{ Marital status (Ref: Not married) } \\
\hline Married & $0.970^{* *}$ & 0.138 & 0.176 & 0.411 & 0.360 & 0.074 & 0.522 & 0.326 & 0.095 \\
\hline Divorced or widowed & $0.518^{* *}$ & 0.168 & 0.074 & $0.529^{* *}$ & 0.156 & 0.076 & 0.183 & 0.142 & 0.026 \\
\hline Children in household & 0.162 & 0.107 & 0.029 & 0.177 & 0.099 & 0.031 & 0.099 & 0.090 & 0.018 \\
\hline Ethnicity: White & $-0.837^{* *}$ & 0.128 & -0.113 & $-0.726^{* *}$ & 0.119 & -0.098 & $-0.534^{* *}$ & 0.129 & -0.072 \\
\hline \multicolumn{10}{|l|}{ Employment (Ref: Employed) } \\
\hline Unemployed & -0.360 & 0.217 & -0.028 & -0.337 & 0.202 & -0.027 & $-0.358^{*}$ & 0.183 & -0.028 \\
\hline Homemaker & $0.378^{*}$ & 0.153 & 0.047 & 0.215 & 0.142 & 0.027 & 0.213 & 0.129 & 0.026 \\
\hline Retired & 0.184 & 0.182 & 0.022 & 0.142 & 0.169 & 0.017 & 0.038 & 0.153 & 0.005 \\
\hline Student & 0.154 & 0.257 & 0.011 & 0.151 & 0.239 & 0.010 & 0.158 & 0.217 & 0.011 \\
\hline Mother's attendance & & & & $0.169^{* *}$ & 0.023 & 0.153 & $0.105^{* *}$ & 0.021 & 0.095 \\
\hline Father's attendance & & & & $0.140^{* *}$ & 0.021 & 0.144 & $0.120^{* *}$ & 0.019 & 0.123 \\
\hline \multicolumn{10}{|c|}{ Parents' religion (Ref: No religion) } \\
\hline Mum and dad same religion & & & & $0.394^{*}$ & 0.170 & 0.062 & 0.098 & 0.155 & 0.015 \\
\hline Mum and dad different relig & gion & & & $0.517^{* *}$ & 0.188 & 0.070 & $0.371^{*}$ & 0.171 & 0.050 \\
\hline \multicolumn{10}{|c|}{ Spouse's religion (Ref: No partner) } \\
\hline Spouse's religion same as $R$ & & & & $0.950^{* *}$ & 0.351 & 0.172 & 0.191 & 0.319 & 0.035 \\
\hline Spouse's religion different & & & & -0.410 & 0.367 & -0.047 & -0.349 & 0.333 & -0.040 \\
\hline Spouse has no religion & & & & $-1.037^{* *}$ & 0.389 & -0.087 & -0.618 & 0.353 & -0.052 \\
\hline Belief in God & & & & & & & $0.704 * *$ & 0.042 & 0.272 \\
\hline \multicolumn{10}{|c|}{ Denomination (Ref: No religion) } \\
\hline Mainline Protestant & & & & & & & $1.395^{* *}$ & 0.149 & 0.194 \\
\hline Evangelical Protestant & & & & & & & $2.048^{* *}$ & 0.145 & 0.328 \\
\hline Black Protestant & & & & & & & $1.594^{* *}$ & 0.224 & 0.140 \\
\hline Catholic & & & & & & & $1.450^{* *}$ & 0.137 & 0.239 \\
\hline Other religion & & & & & & & $1.627^{* *}$ & 0.178 & 0.159 \\
\hline R square & 0.077 & & & 0.207 & & & 0.351 & & \\
\hline N & 3267 & & & 3267 & & & 3267 & & \\
\hline
\end{tabular}


Ingrid Storm and David Voas: The intergenerational transmission

\section{Discussion}

Previous research has shown that change and continuity of religious affiliation and behaviour in the Western world are in large part a result of cohort differences, and age and period effects play only a very small role in influencing religiosity (King-Hele 2011; Voas and Crockett 2005). Identities, beliefs and practices are remarkably stable (on average) over the adult life course, indicating that individual religious involvement is substantially determined in childhood and adolescence by parents, peer groups and the cultural environment. Since religious decline has been shown to be mainly the result of cohort differences, we need to look at how effective parents are at transmitting their religious behaviours to their children in order to fully understand different levels of religiosity such as that between men and women, and different trends of religious decline, such as the discrepancy between the US and other Western countries. Three questions about the nature of intergenerational religious decline were posed in the introduction. The first concerned how widespread and how large religious decline is at the level of families, the second asked whether parental influence is greater in more religious countries, and the third asked which individual variables influence intergenerational transmission of religion and whether these vary between different countries.

At the level of families, the overall difference between respondents and their parents is not very large. In answer to the first question posed in the introduction, intergenerational decline in religiosity takes place because many people are a little less religious than their parents. The decline is on average slow. There are exceptions, such as the unusually rapid religious decline in the Netherlands, but in the vast majority of the countries, there is a consistent loss in religiosity from one generation to the next. The differences we observe in the general levels of religiosity between men and women, and between different countries, are thus likely to be maintained for some time.

At the country level, there was no indication that parents are more influential in religious countries than in secular countries. Our results show that parental influence on religion is remarkably consistent, and the findings are similar when using different measures of religious committment. While the general success of intergenerational transmission varies across different countries and cohorts and between men and women, the impact of parental religiosity relative to other sources of influence is fairly similar across a wide range of countries, and the relationship between the religiosity of parents and children appears linear. Contrary to social learning theory (Jennings et al. 2009: 783), the salience of the behaviour and values to the parents, and the consistency between mother's and father's religion, does not appear to affect transmission rates in a positive way.

In addition to parental levels of religiosity and attendance, there are other individual level variables that influence both religious service attendance and the intergenerational transmisson of religiosity, most notably gender and denominational affiliation. Women are on average more likely than men to be religious and also more likely to inherit their parents' religiosity. Still, the effect of mother's and father's attendance on the respondent appeared to be the same. There are significant associations between religious attendance and denominational affiliation in general, with mainline Protes- 
tants being less likely to attend frequently than Evangelicals, Catholics and non-Christians.

There is little difference between the US and Great Britain in how religion is transmitted from parents to children, whether or not we control for sociodemographic variables or religious denomination. Moreover, it is not only the parental influence that is similar. In both countries, age, gender, ethnicity and marriage to someone of the same religion have strong associations with religious attendance. The only important observable difference is the baseline level of religious attendance. The obvious hypothesis is that the religious environment promotes more religious behaviour in the US and more non-attendance in Britain, whatever the religiosity of the parents. To summarise, the generation gap is larger in Britain than the US but the average difference between children of religious parents and children of nonreligious parents is the same in the two countries.

The results suggest that parents, sociodemographic and contextual variables are important influences on church attendance, but there is no indication that these variables interact. Religious socialisation within families is not any less efficient than it was in the less secular past or in contemporary religious societies. Parents' religiosity is a powerful predictor of individual levels of church attendance, and it has similar effects in very different countries.

\section{Notes}

1 The original variable had 9 categories from 1) Never to 9) Several times a week. The scale has been slightly stretched at both ends by giving 'Never' the value 0 and 'Several times a week' the value 10. There are two reasons for this adjustment. First, the ordinal values do not form an ideal scale. Because most of the middle categories are fairly close together there are good theoretical reasons for acknowledging a more substantial difference between denying any religious attendance and going rarely. It is also worth differentiating between attending several times a week, which in most countries is a sign of very high commitment, and more conventional weekly attendance. Secondly, re-numbering the categories as described causes the relationships to be almost perfectly linear rather than slightly curvilinear, making the graphs easier to read.

2 Respondents whose parents were not present in childhood are treated as missing in the analysis.

3 «Parental attendance» refers to the mean of mother's and father's religious attendance. When only one parent was present in childhood, it is the attendance of this parent.

4 Kelley and De Graaf (1997) offer an alternative hypothesis, that the slope will be steeper in more secular countries. They argue that religious parents work harder to instil religious commitment in places where the religious environment is unfavourable.

5 The original variable had 6 categories: 1) I don't believe in God; 2) I don't know whether there is a God and I don't believe there is any way to find out; 3) I don't believe in a personal God, but I do believe in a Higher Power of some kind; 4) I find myself believing in God some of the time, but not at others; 5) While I have doubts, I feel that I do believe in God; 6) I know God really exists and I have no doubts about it. Categories 3 and 4 were combined as it is not evident that one or the other is more strongly theistic. 
Ingrid Storm and David Voas: The intergenerational transmission

6 In Britain the other categories are 1) CSE or equivalent, 2) O level or equivalent, 3) A level or equivalent, 4) Higher education below degree. In the US they are 1) High School, 2) Junior College, 3) Bachelor's degree.

\section{References}

Bader, Christopher D., and Scott A. Desmond 2006. «Do as I Say and as I Do»: The Effects of Consistent Parental Beliefs and Behaviors Upon Religious Transmission. Sociology of Religion 67(3): 313-329.

Chaves, Mark 2011. American Religion: Contemporary Trends. Princeton: Princeton University Press.

DeVaus, David and Ian McAllister 1987. Gender Differences in Religion: A Test of the Structural Location Theory. American Sociological Review 52(4): 472-481.

Francis, Leslie J. and Laurence B. Brown 1991. The Influence of Home, Church and School on Prayer Among Sixteen-Year-Old Adolescents in England. Review of Religious Research 33(2): 112-122.

Greeley, Andrew and Michael Hout 2006. The Truth About Conservative Christians. Chicago: University of Chicago Press.

Hoge, Dean R., Gregory H. Petrillo and Ella I. Smith 1982. Transmission of Religious and Social Values from Parents to Teenage Children. Journal of Marriage and the Family 44(3): 569-580.

Iannaccone, Laurence R. 2003. Looking Backward: A Cross-national Study of Religious Trends [online]. Unpublished Working Paper, George Mason University. Available from: http:// www.umbc.edu/economics/seminar_papers/LRI.pdf. [Accessed 28 August 2012].

Jennings, M. Kent, Laura Stoker and Jake Bowers 2009. Politics Across Generations: Family Transmission Reexamined. The Journal of Politics 71(3): 782-799.

Kelley, Jonathan and Nan Dirk De Graaf 1997. National Context, Parental Socialization, and Religious Belief: Results from 15 Nations. American Sociological Review 62(4): 639-659.

King-Hele, Sarah 2011. The Dynamics of Religious Change: A Comparative Study of Five Western Countries. Unpublished $\mathrm{PhD}$ thesis in Social Change. University of Manchester.

Myers, Scott M. 1996. An Interactive Model of Religiosity Inheritance: The Importance of Family Context. American Sociological Review 61(5): 858-866.

Ploch, Donald R. and Donald W. Hastings 1998. Effects of Parental Church Attendance, Current Family Status, and Religious Salience on Church Attendance. Review of Religious Research 39(4): 309-320.

Putnam, Robert D. and David E. Campbell 2010. American Grace: How Religion Divides and Unites Us. New York: Simon and Schuster.

Sacerdote, Bruce and Edward L. Glaeser 2001. Education and Religion. Harvard Institute of Economic Research Working Papers 1913.

Sullins, D. Paul 2006. Gender and Religion: Deconstructing Universality, Constructing Complexity. American Journal of Sociology 112(3): 838-880.

Turkheimer, Eric 2000. Three Laws of Behavior Genetics and What They Mean. Current Directions in Psychological Science 9(5): 160-164.

Van Rooden, Peter 2003. Long-term Religious Developments in the Netherlands, C.1750-2000. In The Decline of Christendom in Western Europe, 1750-2000, Hugh McLeod and Werner Ustorf (eds.), 113-129. Cambridge: Cambridge University Press. 
Voas, David and Alasdair Crockett 2005. Religion in Britain: Neither Believing nor Belonging. Sociology 39(1): 11-28.

Voas, David and Ingrid Storm 2012. The Intergenerational Transmission of Churchgoing in England and Australia. Review of Religious Research 53(4): 377-395.

Walter, Tony and Grace Davie 1998. The Religiosity of Women in the Modern West. British Journal of Sociology 49(4): 640-660.

Willits, Fern K. and Donald M. Crider 1989. Church Attendance and Traditional Religious Beliefs in Adolescence and Young Adulthood: A Panel Study. Review of Religious Research 31(1): 68-81. 